\title{
Norwegian patients on generic antihypertensive drugs: a qualitative study of their own experiences
}

\author{
Else-Lydia Toverud • Anne Kjersti Røise • \\ Grete Hogstad • Inger Wabo
}

Received: 17 July 2010 /Accepted: 18 October 2010 /Published online: 23 November 2010

(C) The Author(s) 2010. This article is published with open access at Springerlink.com

\begin{abstract}
Objectives The aim of this study was to investigate experiences with and attitudes toward generic substitution in patients on antihypertensive medication.

Materials and methods Study participants were 22 patients from pharmacies in Oslo who had taken brand antihypertensive products as well as substituted generic products. Five focus- group discussions were held.

Results Only a few participants claimed to take their medications as prescribed. Most reported low drug adherence before and after generic substitution. Fourteen said that their blood pressure was not under control. Most patients did not know what it meant to get a generic product. They normally accepted what the pharmacy offered, even if they thought the generics were of a lower quality than the brand products. Five participants experienced new side effects. Differences in name, color, form, or taste caused confusion. The patients had been told in the pharmacy that the effect of a generic product was as good as that of the brand product but were still confused, as in most cases the doctor said nothing to them about the substitution.

Conclusion Generic substitution works well in Norway as an economic health strategy, but drug adherence remains suboptimal under those circumstances. Patients are insecure with respect to the difference between the old and the new
\end{abstract}

E.-L. Toverud $(\bowtie) \cdot$ A. K. Røise $\cdot$ I. Wabø

Department of Social Pharmacy, School of Pharmacy,

University of Oslo,

Oslo, Norway

e-mail: e.1.toverud@farmasi.uio.no

G. Hogstad

Alpharma Skøyen,

Harbitzalleen 3, Skøyen,

Oslo, Norway product when it comes to the drug's physical attributes and perceived quality. Patients would feel safer if the doctor had a more active role in informing them about the system.

Keywords Generic substitution · Hypertension · Drug adherence · Drug information · Focus-group discussions

\section{Introduction}

In the Nordic countries, generic substitution was introduced in 1995 in Denmark [1], followed by Norway in 2001 [2], Sweden in 2002 [3], and Finland in 2003 [4]. This was a less radical measure than would be the introduction of generic prescribing-the main form for prescribing in Great Britain and a few other European countries [5]. Generic substitution is an economic health strategy to diminish the government's refunding costs of prescription drugs $[2,3,6]$. It is essential for patients as well as for health care personnel to be aware that when compared with the brand product, the generic alternative contains the same amount of the same active compound and is of the same quality and safety [7]. However, the patient on the receiving end is getting a product with a different brand name and possibly in a different form, size, color, or taste. Consequently, challenges arise when it comes to taking the drug appropriately, and the patient may become confused [7].It is also important to be aware that it has been known for many years that drug adherence without generic substitution is on average only $50 \%$ for patients taking chronic medication [8].

Generic prescribing is authorized in Norway, but the system is not being practised in more than about $2 \%$ of prescriptions [9]. The use of generic substitution has, however, risen dramatically and almost reached $40 \%$ of the market share in defined daily doses (DDD) in 2008/2009 [7]. 
Generic substitution was introduced in Norway at the same time as a new pharmacy act. This implied that, for the first time, international chains could own pharmacies. The different chains are licensed to have different products in stock. In other words, patients who use more than one pharmacy may be getting different generic products. The pharmacist is obliged to suggest substituting the prescribed pharmaceutical product for the cheapest interchangeable generic unless the physician has marked on the prescription that substitution should not take place. The patient can, however, insist on the brand product but will then have to pay an additional fee. As the government in Norway refunds most prescription drugs, the concept of additional fees was relatively new to the patients, even though other similar strategies have been tried out for about a 10-year period. [2]. However, no marked difference between social classes has been shown when it comes to the use of generic drugs, unlike in many other countries [10].

Using a structured questionnaire, our group previously interviewed 174 patients who took both brand and generic antihypertensive products [7]. We found that as many as one in three said that generic substitution made it more demanding for them to cope with their medication. Three out of ten said they were anxious when they started to use a generic product [7]. We also found that $8 \%$ of the patients said they noticed a poorer effect of the new drug, and $15 \%$ experienced new side effects [7]. In Sweden, it was found that increased generic market shares increased the number of reported side effects for seven of 15 active ingredients [11]. In Denmark, $6 \%$ in a study of 86 patients experienced more side effects [12]. In another Norwegian study, one in three patients reported new side effects or a change in the effect of the drug after generic substitution [13]. In a US study, between $14 \%$ and $54 \%$ of 500 patients, depending on their medical condition, claimed that generic drugs were less safe than the brand products [14].

The aim of this study was to investigate the views on and attitudes toward generic substitution in patients on antihypertensive therapy when they were allowed to talk freely in focus groups about their own experiences. How did the substitution affect their drug adherence, and how knowledgeable were they, in fact, about the situation?

\section{Patients and methods}

\section{Patients}

The study group consisted of 22 patients ( 15 men, seven women) using five pharmacies in Oslo. Patient age range was 51-76 years. All informants had experience with antihypertensive drugs both as brand products and then as substituted generic products.
Method

Five pharmacies where generic substitution occurred to a high degree and that were geographically spread out across the city were selected based on information provided by the three large pharmacy chains that exist in Norway. An information meeting about the study was held with the personnel in each pharmacy. Patients between 50 and 80 years of age were asked to take part in the study if they had been taking brand antihypertensive drugs and later changed at least once to a generic product. Patient recruitment was conducted from April to September 2004. The pharmacies received 30 invitation letters each to give to patients who fulfilled the criteria for participation. The patients were also informed in person. Those who agreed to participate had to send their written reply in a prestamped envelope. Focus-group interviews were used as the research method. Five groups of five patients each were formed randomly according to when the returned envelopes were received. Three persons never turned up. A simple questionnaire was handed out at the beginning of each session to obtain some background information about the patients. An interview guide that included the main areas to be discussed was used. The areas were: participants' perception of their drug adherence; participants' knowledge about generic substitution; possible effect of generic substitution on their drug adherence; possible effect of the physician's attitude toward generic substitution in relation to their adherence; and possible effect of the pharmacist's behavior in relation to their adherence.

The first focus-group discussion was the pilot study. As nothing needed to be changed in the interview guide after that first study, the study was included in the results as one of the five focus-group discussions. The same researcher did all the focus-group interviews. A note-taker was present at all interviews and was consulted by the facilitator before data analysis. Each focus group lasted between 1.5 and $2 \mathrm{~h}$. The patients gave their informed consent in writing. The study was approved by the Norwegian Regional Ethics' Committee and the Norwegian Social Science Data Services. The group interviews were recorded, transcribed, and analyzed by the data program QSR Nudist N4 Classic. This method sorts data according to relevant categories and topics to get a better overview of the information collected. The categories were the same as the areas mentioned above as main areas of the interview guide.

\section{Results}

Patient background information

Nineteen of the 22 participants were diagnosed with hypertension, whereas three suffered from various cardiac/ 
cardiovascular conditions. Most participants had used antihypertensive medicines for $>10$ years. Table 1 shows more detailed information about participants' drug use. No patient used drugs extensively.

Patients' perception of their own drug adherence

Only a few patients reported that they took their medication as prescribed, and as many as half of them said that they omitted taking a dose quite often. Especially the evening, the dose was easy to forget, and if they were busy or on holiday, not all doses were usually taken. Several informants claimed to be sceptical about using drugs in general and never felt at ease about taking any kind of medication. However, they explained that they had made a decision to take their antihypertensive medication. One informant was explicit about not being alive without it. In some groups, patients were afraid of becoming addicted to the drugs and were convinced that that can happen very easily with any form for drug. They felt that it would be an especially unfortunate outcome if they were to become addicted to antihypertensive drugs, as they were of the opinion that these drugs have many adverse reactions. The participants in all five groups were, in fact, very preoccupied with adverse drug reactions, and their opinion was that, apart from forgetfulness, fear of such reactions was the most usual reason for nonadherence.

In one group, participants talked about the well-being they felt when being adherent. One person said:

"I believe that it has a certain psychological effect. As long as I take my medicine every day, and at the same time every day, I know that I am on the safe side. What might happen afterwards is not my fault. I have done what I could."

On the other hand some patients expressed the feeling that it did not matter if they forgot to take the tablets, as hypertension in their opinion was not a serious condition. For example, one person said:

"I forget because I look at myself as a healthy person, something I have always been."

A few said that "their body told them" if they had not taken the tablets, whereas others meant that it was better to rely

Table 1 Daily drug use of the 22 patients in the study

\begin{tabular}{lc}
\hline & No. of patients \\
\hline One antihypertensive drug & 11 \\
Two antihypertensive drugs & 11 \\
Regular, additional use of prescribed medicines & 10 \\
Regular use of over-the-counter medicines & 5 \\
Taking more than seven tablets per day & 3 \\
\hline
\end{tabular}

on a "dosette" box. Fourteen patients claimed that their blood pressure was still too high. Eight said, however, that they had a normal blood pressure. Those eight were convinced that it was because of their medication.

Patients' knowledge about generic substitution

When the patients were asked directly what it meant to get a generic product, most answered that they did not know. Some were also of the opinion that the pharmacists were educated enough to know what to give them and that they therefore had no need to bother. One informant had this answer:

"It is when they give you something else in the pharmacy without having to phone to the doctor to ask for permission."

There were a few, however, who said they knew that the active ingredient had to be the same whereas the excipients could be different. Many participants said that they often asked for the brand medicine when they were given generics in the pharmacy - to feel safe:

"After all you prefer to have what the doctor has prescribed."

They normally accepted what the pharmacy offered. By the time of the interview, 19 of 22 patients used generic products. Three had changed back to the brand product. One participant said she hoped they told her the truth in the pharmacy when they said that she got a drug that was as good as the brand product, even if it was cheaper. Others claimed that if the doctor and the pharmacist had said the same thing, they would not have thought so much about it when the drug was changed in the pharmacy. One said:

"The doctors prescribe what they find when they look in their book, and the pharmacists sell you what they find in their shelves, isn't it"?

In what way does generic substitution influence adherence?

There was a big variation in time since the different participants started generically substituted products. Some had used them since the system started, whereas a few had used them only for some weeks. Most patients had had the product changed once or twice since they got the prescription with the brand name. One person had received four different generic products on four different occasions. All participants indicated that they heard that the new product was meant to have the same effect as the brand drug. Some were explicit about the fact that they understood the situation and explained that they first used the tablets they had at home, which had a different name, and 
then started with the new ones. However, at the same time, even if they took their generic products, almost every participant was of the opinion that the generic product was of a lower quality than the brand product. One lady expressed it like this:

"It is probably good enough for me. It is like when you buy a pullover which is not so expensive. It can still be warm enough. Or you can buy a Rolex watch in Singapore. It still works".

When they talked about how differences between the products could be a reason for nonadherence, they mainly talked about the physical differences, such as form, color, and size. One person said:

"It is confusing now when I get square tablets. I used to take round ones".

A few had problems with the new tablets being too big for their dosette. This messed up their adherence as a result. One ended up not knowing what she took after she had forced the tablets into the dosette box:

"When I press the lid on now, some of the tablets break, and then I don't know what I take".

A few felt that their adherence had deteriorated after they changed to a blister pack, as it was irritating to have to press the tablets out. Others missed the blister pack they had before, where they could see if the tablet had been taken or not.

The participants were also discussing whether changes in effect/side effects might have changed their adherence. Five reported that they experienced new side effects when starting with generics and had therefore at first been a bit apprehensive about taking the new medication. Three wondered, however, if the dizziness and/or sickness was "psychological," as they had expected something "bad" to happen. One person was sure that the new side effect she felt came from a new excipient, as she said she knew that the active ingredient was the same. All in all, there was a general agreement that to switch to a generic product had not changed their drug adherence markedly. However, they more or less agreed that it was "as bad as before". There did not seem to be any gender or age differences regarding how they took their tablets.

Effect the physician's attitude may have on the patient's adherence after generic substitution

Most participants expressed a great trust in their doctor. In particular, women in the study spent considerable time discussing that topic.

"You believe in your doctor, so when you come to the pharmacy and they give you something else than what the doctor has prescribed, you feel insecure. You sit at home and think that the new tablets don't work as the old ones, because if it is the same thing, why did not the doctor prescribe it?"

Another expressed the trust like this:

"I don't think it is all right to use medicines, but I feel that if I don't take what the doctor says, something bad can happen".

However, in general, the informants had the impression that doctors could be more updated and that the situation would be easier if the doctor told them they might get another product than the prescribed one. Some also thought it a good idea if the doctors more often prescribed generic products. One half of the patients said they had not thought about telling their doctor that the drug was changed by the pharmacy or that they had not told the doctor because they felt uncomfortable doing so. The other half had told their doctors, and most doctors had answered that the effect on blood pressure was the same. However, only a few doctors prescribed the generic product the next time. There were also doctors who had been negative, and one informant said:

"I said to my doctor that I don't get the medicines he prescribes. He answered that he thought the changing system is a lot of nonsense".

Effect of the pharmacist's behavior on the patient's adherence

Participants were asked to tell where they got their information on generic substitution. Every person claimed that it came from the pharmacy, and many added that they had never heard about the system before they were offered such products. Some had read about it in the newspaper afterwards. They all indicated that the pharmacy personnel said that the generic product was as good as the brand product and that it was cheaper. One added:

"I have changed into several new products. Every time they ask if it is OK that I change, and every time the new one turns out to be cheaper. So you see, it is only about economy".

Several patients said they trusted the pharmacy, whereas others said they felt that they just had to trust them:

"When they say it is the same ingredient, I have to trust them, I have no other choice. You cannot say to them: sorry, you are mistaken (laughing)".

It was a general opinion that the pharmacies were too active in having them change products. Some felt it very unpleasant to have to negotiate when they wanted the 
prescribed drug. In fact, many were of the opinion that the pharmacies produced their own cheap products and therefore wanted so much to sell them.

\section{Discussion}

Patients in this study were all taking brand hypertensive products before they had their medication substituted at least once into generics. Other studies have already shown that generic substitution often confuses people [7, 11-14]. One study was done by our group [7] where we showed, by a quantitative method, that patients felt anxious and insecure about generic substitution. That caused an additional challenge for drug adherence. Adherence after generic substitution has also been studied using prescription data bases. In such a scenario, it is only possible to look at results on a group level without knowing what is really taken by the individual [15]. Such results are even more difficult to use in a country such as Norway, in which the state pays as much as $70 \%$ of total drug expenditures.

The aim of using focus groups was to determine in more detail how the individual patient experiences the situation with generic substitution. A focus group interview is a qualitative research method that can be especially useful when the topic is sensitive. Patients are, in general, admitting more when they get together and hear each others' stories [16]. This is shown in the results of the study reported here, when the antihypertensive patients talked about how their drug adherence has never been good and in fact only eight of them claimed that their blood pressure is under control. A few also added that their drug adherence deteriorated after generic substitution. Whereas $17 \%$ of participants in the quantitative study said they quite often did not take their medication as prescribed, in this study, $90 \%$ said the same thing. This finding illustrates what can be revealed when using focus groups. It can be argued that there is a limitation per se to involve few participants. However, we consider using different methods to find as much information about a topic as possible extremely useful. It is also an important factor that we had participants from the same city in the two studies.

Participants were uncertain about how the system with generic substitution really worked. As most of them repeatedly received new generic drugs in the pharmacy, and as the tablets often changed in size, color, or taste, they were often of the opinion that the pharmacist gave them what was on hand, and it was a general opinion that they got drugs of lower quality. When compared with the quantitative study in which $15 \%$ of participants claimed to have experienced new side effects [7], 23\% claimed the same in this study. This is probably not a bigger difference than may be found between any two different studies; if anything, the patients in this study admitted more because they were participating in focus groups.

In Norway, as much as $10 \%$ of the population is using antihypertensive drugs [17]. As generics have risen to $40 \%$ of the market shares, many hypertensive patients are offered/ using generic drugs. It is therefore a big challenge for healthcare personnel to help the patients understand the system so they do not end up with an even poorer drug adherence than before. In the quantitative study, for instance, it was found that one in 20 patients took the original product as well as the generic [7].

Patients in our study had a great trust in their doctor. However, in general, they felt they did not get information from him/her about being given a different product (generic) than the prescribed (brand name) one when they went to the pharmacy. Half the patients had told the doctor afterwards about the substitution, but many doctors did not support it. Also, when we studied generic substitution in one of Norway's biggest hospitals, we found that doctors took little part in supporting the system [18]. As the participants in this study were allowed to talk freely in the focus groups, it was quite clear that they felt the pharmacy personnel were pressing them too hard to accept generic products. It was also because of the open discussion that participants expressed they often thought that either the doctor or the pharmacist had to be wrong. This study therefore shows better than other studies how important it is that doctors play a more active role in providing information about generic substitution.

\section{Conclusion}

Generic substitution works well in Norway as an economic health strategy. However, drug adherence remains suboptimal under those circumstances. Patients are insecure about the situation with respect to the difference between the old and the new product when it comes to the drug's physical attributes and perceived quality. New side effects and a poorer effect were reported. The general opinion of patients is that they would feel safer if the doctor had a more active role in informing them about the system.

Open Access This article is distributed under the terms of the Creative Commons Attribution Noncommercial License which permits any noncommercial use, distribution, and reproduction in any medium, provided the original author(s) and source are credited.

\section{References}

1. Møller Pedersen K (2003) Pricing and reimbursement of drugs in Denmark. Eur J Health Econ 4(1):60-65 
2. Håkonsen H, Horn AM, Toverud EL (2009) Price control as a strategy for pharmaceutical cost containment - What has been achieved in Norway in the period 1994-2004? Health Policy 90:277-285

3. Andersson KA, Petzold MG, Allebeck P, Carlsten A (2008) Influence of mandatory generic substitution on pharmaceutical sales patterns: a national study over five years. BMC Health Serv Res 29(8):50

4. Timonen J, Karttunen P, Bengstrøm M, Ahonen R (2009) The impact of generic substitution on the turnover and gross margin of pharmaceutical companies a survey 1 year and 5 years after the introduction of generic substitution in Finland. Health Policy 92 $(2-3): 116-123$

5. Ryan M, Yule B (1993) The way to economic prescribing. Health Policy 25(1-2):25-38

6. Andersson K, Bergstrøm G, Petzold MG et al (2007) Impact of a generic substitution reform on patients' and society's expenditure for pharmaceuticals. Health Policy 81:376-384

7. Håkonsen H, Eilertsen M, Borge H, Toverud EL (2009) Generic substitution: an additional challenge for adherence in hypertensive patients? Curr Med Res Opin 25(10):2515-2521

8. Morris LS, Schulz RM (1992) Patient compliance - an overview. J Clin Pharm Ther 17:283-295

9. Nelson S, Slørdal L, Spigset O (2006) Generic drugs instead of brand drugs prescriptions - long overdue. Tidsskr Nor Laegeforen 126(4):441-443
10. Mendis S, Fukino K, Cameron A et al (2007) The availability and affordability of selected essential medicines for chronic diseases in six low- and middle-income countries. Bull World Health Organ 85(4):279-288

11. Hellstrøm J, Rudholm N (2004) Side effects of generic competition? Eur J Health Econ 5(3):203-208

12. Andersen MLE, Laursen K, Schaumann M et al (2000) How do patients evaluate the newly introduced system of substituting prescriptions? Ugeskr Laeger 162:6066-6069

13. Kjoenniksen I, Lindbaek M, Granas AG (2006) Patients' attitudes towards and experiences of generic drug substitution in Norway. Pharm World Sci 28:284-289

14. Ganther JM, Kreling DH (2000) Consumer perceptions of risk and requiredcost savings for generic prescription drugs. J Am PharmaceuticalAssoc 40:378-383

15. Van Wijk BL, Klungel OH, Heerdink ER, de Boer A (2006) Generic substitution of antihypertensive drugs: does it affect adherence? Ann Pharmacother 40:15-20

16. Wibeck V (2000) Fokusgrupper. Om fokuserade gruppeintervjuer som undersökningsmetod. Studentlitteratur, Lund

17. The Norwegian Association of Pharmaceutical Manufacturers. Facts and figures $2010 \mathrm{http}: / / \mathrm{www} .1 \mathrm{mi}$. no/91/Legemiddelstatistikk/ Tall_og_fakta_2010_web_4rbVu.pdf.file (Accessed 8.10.2010)

18. Håkonsen H, Hopen HS, Abelsen L, Ek B, Toverud EL (2010) Generic substitution: a potential risk factor for medication errors in hospitals. Adv Ther 27:118-126 